DOI

http://dx.doi.org/10.1590/2236-463320151002

A New Way of Thinking Time, a New

Way of Thinking History: the nineteenth

Century in Spain

\title{
Una nueva forma de pensar el tiempo, una nueva forma de pensar la historia: el siglo XIX en España ${ }^{1}$
}

\section{Ana Isabel González Manso}

Universidad País Vasco, Bilbao - País Vasco, España

e-mail: anaisabel.gonzalez@ehu.es

\section{Resumen}

Desde finales del siglo XVIII se empieza a percibir en España una nueva forma de pensar el tiempo que tendrá importantes repercusiones en la forma de pensar la historia y de Ilevar a cabo la práctica política. En realidad asistimos a la coexistencia y entrelazamiento de diferentes temporalidades aunque el presente estudio va a centrarse particularmente en aquella que va a concebir el tiempo como una oportunidad, con sus avances y retrocesos, con sus dudas y problemas. Nos interesa analizar las diferentes soluciones a los problemas que esta nueva temporalidad suscitó a la hora de abordar el estudio histórico y su plasmación, al mismo tiempo, en propuestas políticas.

\section{Abstract}

Since the last years of the 18th century, we may appreciate in Spain a new way of thinking time. This way will greatly affect the way of thinking history and, as a consequence, of carrying out the political action. Really, different temporalities coexist and mix together in a very complex fashion; the present paper, however, is focused on the way of thinking time as an opportunity, with its advances and backings down, doubts and problems. We analyze the different solutions to the problems arisen by that temporality concept in the field of historical study as also in the political action.

Palabras-clave

temporalidad, Historiografía, tradición, Modernidad, España, siglo XIX

Keywords

temporality, Historiography, tradition, Modernity, Spain, XIX century
Este texto fue en parte presentado en el Colóquio Internacional: Experiências de Tempo nos Séculos XVIII e XIX (Iberconceptos 3.) desarrollado en Sao Paulo del 23 al 25 abril 2014. Quería agradecer particularmente a Joao Paulo Pimenta, Fabio Wasserman, Francisco A. Ortega, Guillermo Zermeño, Maria Elisa Noronha de Sá, Javier Fernández Sebastián y en general a todos los miembros del grupo, sus aportaciones a la mejora del presente trabajo, que ha sido realizado gracias a una beca FPI de la UPV (Bilbao), España. 
2

MENÉNDEZ PELAYO, Marcelino. Advertencias preliminares, escrito en julio 1910. Libro I. En:__ (aut.). Historias de los heterodoxos españoles. Barcelona: Linkgua, 2011. p.46.

STÜCKRATH, Jörn. The Meaning of History. A modern Construction and Notion? En: RÜSEN, Jörn (ed). Meaning and Representation in History. New York-0xford: Berghahn Books, 2006. p.66.

4

Ibidem, p.69.

5

lbidem, p.73.

6

KOSELLECK, Reinhart. Cambio de experiencia y cambio de método. Un apunte históricoantropológico. En:___ (aut.). Los estratos del tiempo: estudios sobre la historia. Barcelona: Paidós, 2001. p.43-92.

7

Idem. Continuidad y cambio en toda historia del tiempo presente. Observaciones históricoconceptuales. En:___ (aut.). Futuro pasado. Para una semántica de los tiempos históricos. Barcelona: Paidós, 1993. p.130.

8

Es muy abundante la bibliografía sobre la España del siglo XIX. Mencionamos solamente algunas de las obras más recientes que presentan un enfoque metodológico que consideramos interesante: PORTILLO VALDÉS, José María. Revolución de nación. Orígenes de la cultura constitucional en España, 1780-1812. Madrid: Centro de Estudios Políticos y Constitucionales 2000; PÉREZ GARZON, Juan Sisinio (ed.). La gestión de la memoria. La historia de España al servicio del poder. Barcelona: Crítica, 2000; FERNÁNDEZ SEBASTIÁN, Javier; FUENTES, Juan Francisco (dirs.). Diccionario político y social del siglo XIX español. Madrid: Alianza, 2002; GARCíA CARCEL, Ricardo (coord.). La construcción de las historias de España. Madrid: Marcial Pons, 2004; FONTANA, Josep. La época del liberalismo. En: ___ _ VILLARES, Ramón (dirs.). Historia de España. Volumen 6. Madrid: Marcial Pons, 2007; RÚJULA, Pedro; CANAL, Jordi (eds.). Guerra de ideas. Política y cultura en la España de la guerra de la independencia. Madrid: Marcial Pons, 2011; ÁLVAREZ JUNCO, José (coord.). Las historias de España. Visiones del pasado y construcción de identidad. En: FONTANA, Josep; VILLARES, Ramón (dirs). Op. Cit., volumen 12.
Introducción

Desde finales del siglo XVIII en España se percibe una nueva forma de pensar el tiempo, que queda perfectamente sintetizada en la frase de Marcelino Menéndez Pelayo "Nada envejece tan pronto como un libro de historia".2 Si el cambio continuo es sinónimo de modernidad, ¿qué sentido tuvo la historia en un mundo, el decimonónico, que empezó a vivir y percibir el presente como un tiempo nuevo? ¿Hasta qué punto aparecen interrelacionados pasado, presente y futuro? Ante estas cuestiones se encontraron los intelectuales españoles del siglo XIX en una situación además, convulsa, y de importantes cambios politicos.

Para Jörn Stückrath "meaning (sinn) of history" como expresión o idea no viene de la Antigüedad clásica, ni del pensamiento cristiano o de la llustración sino que "is linguistically and notionally a modern coinage" ${ }^{3} y$ vendría a sustituir a las viejas expresiones histórico-metafísicas de "plan", "purpose" o "goal"." En definitiva vendría a sustituir a un Dios creador de la historia que autores como Kant, Schelling o Hegel plasmaron en la metáfora del teatro divino donde "the acting politician as actor, the designing God as autor of the play and the philosophical spectator who, from his seat in the box, sees through the coherence of the great drama". Stückrath no deja de reconocer la polisemia de la expresión "meaning of history".

Reinhart Koselleck introduce, en el proceso de reescritura de la historia, la variabilidad de interpretaciones del pasado. ${ }^{6}$ Según este autor, para percibir el pasado es necesario traducirlo a nuestro propio lenguaje, lo cual implica, aunque sea hermenéuticamente, introducir la tradición pasada en la propia experiencia: "Siempre se ha reescrito para corregir lo falso; reescribir porque la perspectiva cambiante del presente permite descubrir algo nuevo es algo que sólo se hace desde el siglo XVIII". El hecho de que los intelectuales decimonónicos tuvieran nuevas concepciones temporales va a conllevar el que reescribiesen el pasado de formas diferentes.

Nos proponemos investigar en este trabajo cómo el cambio en la percepción de la temporalidad influyó en ciertos intelectuales españoles del siglo XIX a la hora de escribir o de pensar la historia. No vamos a centrarnos especificamente en estudiar las diferentes expresiones de la nueva concepción temporal, sino en relacionar a éstas con la manera de pensar la historia.

¿Qué significados le dieron estos intelectuales de inicios de la modernidad a "sentido de la historia"?; ¿se perciben diferencias entre el periodo de la llustración y la mitad del siglo XIX?; ¿lo utilizaban en un sentido moderno o todavía con las antiguas afecciones? En función de las respuestas que demos a estos interrogantes podremos entender mejor la manera de acercarse al pasado y las características que adoptó la práctica de la ciencia histórica. Vamos a intentar mostrar cómo un grupo importante de intelectuales, desde finales del siglo XVIII pero sobre todo hacia la mitad del siglo XIX, pensaron el tiempo y la historia de una forma moderna, y qué diferentes soluciones propusieron a los problemas que tal cambio les produjo.

\section{Antes de comenzar, unas breves pinceladas históricas ${ }^{8}$}

Con una progresiva pérdida por parte de España de protagonismo internacional a lo largo del siglo XVIII, entramos en el siglo XIX con un pacto entre el gobierno español y el francés que permitirá la entrada del ejército de Napoleón en España en 1808 para facilitarle la ocupación de Portugal. Finalmente las intenciones de Napoleón fueron más ambiciosas, ocupando también España y provocando la abdicación del rey Carlos IV en su hijo 
9

GONZÁLEZ MANSO, Ana Isabel. Tolerancia Religiosa y Modelo de Iglesia en España en la Primera Mitad del Siglo XIX. Historia Constitucional, Oviedo, n.15, p.113-153, septiembre 2014. Disponible en: <http://www. historiaconstitucional.com>. Acceso el: 15 oct. 2014.

10

VARELA SUANZES-CARPEGNA, Joaquin. La Monarquía doceañista (1810-1837). Madrid: Marcial Pons Historia, 2013.
Fernando VII (ambos retenidos en Francia) y el inicio de la Guerra de la Independencia contra Francia (1808-1814). Esta contienda tendrá diferentes consecuencias, entre ellas la expulsión francesa del territorio y desde el punto de vista político, la elaboración en Cádiz de la Constitución liberal de 1812.

Con la llegada del rey Fernando VII a España el 22 de marzo de 1814 y su negativa a jurar la Constitución recién elaborada, se iniciarán seis años de gobierno absolutista que llevaron a la cárcel o al exilio a muchos liberales y afrancesados y que solo finalizará en enero de 1820 con el pronunciamiento militar (exitoso pues habia habido varios anteriores que no lo consiguieron) en la localidad sevillana de Las Cabezas de San Juan del teniente coronel Rafael de Riego. Así dará inicio el Trienio liberal, 1820-1823, que supondrá el restablecimiento de la Constitución de 1812 y su jura por Fernando VII en las Cortes del 9 de julio de 1820.

Este periodo estará marcado por los intentos desde las Cortes de desarticular legalmente el Antiguo Régimen, de hacer frente a una importante deuda y de poner en marcha el edificio liberal proyectado en la Constitución gaditana, completándolo con leyes nuevas que redundasen en los objetivos previstos. Será un periodo marcado por las tensiones entre el Palacio y las Cortes y entre los mismos liberales dadas las diferentes maneras de entender la construcción del régimen liberal y los problemas prácticos vinculados. También, debido a la actitud de parte del clero que irá tomando posiciones claramente contrarias a las medidas de reforma liberales, se irá produciendo una brecha religiosa entre los partidarios de una Iglesia que siguiese marcando la política y los partidarios de separar religión e Iglesia como institución a reformar urgentemente. ${ }^{9} \mathrm{~A}$ finales de 1823 se pondrá fin a la experiencia liberal, con la entrada del ejército organizado por la Santa Alianza europea para atajar un gobierno que era considerado demasiado revolucionario para la Europa de la Restauración, en la que dominaban las fuerzas contrarrevolucionarias; experiencia liberal que además no contó con el apoyo generalizado de la población española.

Asi se produjo el retorno a un nuevo periodo absolutista, marcado por un nuevo exilio de numerosos liberales en Francia e Inglaterra y que duró hasta la muerte del rey Fernando VII en 1833. Al dejar éste establecida su sucesión en su hija Isabel en detrimento del hermano del rey, D. Carlos María Isidro, se dará inicio a la primera guerra carlista (guerra con muchas connotaciones, no solo dinásticas, pues implicaba diferentes visiones políticas, económicas, sociales y religiosas) que durará hasta 1839. Hasta 1850, periodo que estamos analizando principalmente en este trabajo, se sucederán diferentes gobiernos liberales moderados y progresistas así como la aprobación de diferentes Constituciones (el Estatuto Real de 1834, la Constitución de 1837 y la Constitución de 1845 que terminará por consagrar la soberanía compartida Rey-Cortes). ${ }^{10} \mathrm{~A}$ través de éstas, los políticos tratarán de articular el nuevo edificio político, la cohabitación de la Corona y de la representación parlamentaria (en dos cámaras), la resolución de los enormes problemas económicos de la Nación así como el desmantelamiento de las estructuras de antiguo régimen vigentes. El margen parlamentario del régimen será limitado, cobrando importancia en esta evolución los debates en las Cortes, la prensa y las tertulias en las que participaron los exiliados. El periodo en general estará marcado por la inestabilidad política, por las tensiones dentro del ejército, por las divisiones entre los progresistas así como por el inicio de la práctica conspirativa y del pronunciamiento por parte de los moderados como instrumento de oposición. 
RUSEN, Jörn. What does "Making sense of history" mean? En:____ed.). Meaning and Representation..., Op. Cit., p.2.

WHITROW, Gerald James. El tiempo en la historia. Barcelona: Crítica, 1990.

RUSEN, Jörn. Sense of History: What does it mean? With an Outlook onto Reason and Senselessness. En:___ (ed.). Meaning and Representation..., 0p. Cit., p.41.

14

HARTOG, François. Régimes d'historicité. Paris: Seuil, 2003.

15

CHARLE, Christophe. Discordances des Temps. Paris: Armand Colin, 2012

16

SIMAY, Philippe. El tiempo de las tradiciones. Antropología e historicidad. En: DELACROIX, Christian; DOSSE, François; GARCÍA, Patrick (eds.). Historicidades. Buenos Aires: Waldhuter, 2010. p.309-321.

HOBSBAWM, Eric; RANGER, Terence (eds.). The Invention of Tradition. Cambridge: Cambridge University Press, 1983.

ALEXANDER, James. Three rival views of tradition (Arendt, Oakeshott and Maclntyre). Journal of the Philosophy of History, Leiden, n.6, p.20-43, 1 semestre 2012; en el mismo sentido SIMAY, Philippe. Op. Cit., p.311.

SIMAY, Philippe. Op. Cit., p.316.

20

RÜSEN, Jörn. Tradition: a principle of historical sense-generation and its logic and effect in historical culture. History and Theory, n.51, p.4559, December 2012

\section{Una nueva forma de pensar el tiempo}

El concepto de tiempo se puede considerar como una consecuencia de nuestra experiencia del mundo. ${ }^{11}$ Como tal, nuestra idea del tiempo muestra una continua evolución que se manifiesta en la cada vez mayor importancia de los tiempos verbales en el desarrollo del lenguaje, y en la mayor diferenciación entre pasado, presente y futuro. La conciencia del tiempo ha cambiado a lo largo de los siglos y de las culturas. En el Occidente cristiano los tiempos cíclicos de los antiguos griegos, en los cuales las situaciones sociales y políticas nacian, se desarrollaban y morian una detrás de otra, fueron suplantados por el Cristianismo con un único tiempo lineal que empezaba con la creación del mundo y acababa con su fin, teniendo su punto central en Cristo. En el siglo XVIII, inicio temporal de nuestro análisis, el optimismo intelectual que caracterizó a la llustración, "se basaba en una actitud con respecto al tiempo que miraba hacia adelante", fundamentalmente a una idea de tiempo benefactor, a una idea de progreso que se verá reforzada por la posterior teoría de la evolución biológica de Darwin. ${ }^{12}$ El concepto de historia sufrirá unas vicisitudes similares al concepto de tiempo y es por eso que en el desarrollo siguiente los dos términos aparecerán fuertemente vinculados. La nueva conciencia del presente influirá en la relectura del pasado en función de los deseos de futuro. ${ }^{13}$ Creemos que solo a través de la comprensión de las diferentes maneras de reescritura de la historia que estarán presentes desde finales del siglo XVIII, se pueden entender las concepciones temporales y viceversa.

De una manera un tanto reduccionista, los historiadores han ligado el inicio de la modernidad con solo una o dos maneras de concebir el tiempo. Por lo general se ha insistido en una interpretación compartimentada, un tanto rígida, que contemplaba fundamentalmente una visión de progreso, de mirada única hacia el futuro por parte del mundo liberal y en cambio una retrógrada, inmovilista por parte del mundo no liberal. Esta postura empezó a cambiar a partir de obras como la de François Hartog, que a través de la categoría analítica de "regímenes de historicidad" defendió que éstos no existían en estado puro, por lo que podíamos suponer que en cada tiempo histórico se superpondrian viejos y nuevos regímenes creando así pues un amalgama más complejo de lo inicialmente propuesto. ${ }^{14}$ Por su parte, Christophe Charle dio un paso más al destacar las "discordancias de tiempos" en la sociedad decimonónica. ${ }^{15}$

También ha ayudado a complejizar el proceso una interpretación menos estática del concepto de tradición, es decir dejar de ver como opuestos o incompatibles, a modernidad y a tradición. Si entendemos el concepto de tradición como la transmisión intergeneracional de elementos culturales, no es posible concebir la convivencia humana sin tradición. Se ha atribuido al concepto tradición dos caracteristicas: antigüedad y continuidad, atribución con la que autores como Philippe Simay ${ }^{16}$ o James Alexander no están de acuerdo, pues son frecuentes las tradiciones "inventadas", ${ }^{17}$ y porque es imposible una transmisión integral de las mismas dado que en este proceso, la tradición sufre transformaciones por parte de aquellos que realizan la transferencia, y que esas transformaciones pueden ser consideradas legítimamente como tradicionales. ${ }^{18}$ Las tradiciones "no pueden ser asimiladas a una herencia recibida pasivamente porque siempre implican un proceso de recepción y de reconstrucción", deben de ser pensadas en relación con el presente. ${ }^{19}$ Por su parte Jörn Rüsen al definir tres formas de tradición, "functioning", "reflective" y "dormant", ${ }^{20}$ introdujo, por la persistencia de 
21

CID, Gabriel. "Los últimos tiempos están encima de nuestras cabezas". Temporalidad y escatología en el siglo XIX hispanoamericano. De próxima aparición.
ASSMANN, Aleida. Transformations of the Modern Time Regime. En: LORENZ, Chris; BEVERNAGE, Berber (eds.). Breaking up Time. Negotiating the Borders between Present, Past and Future. Bristol: Vandenhoeck and Ruprecht 2013. p.39-56. esta última forma en el inconsciente cultural, la posibilidad de plasmar los sueños de cambio y de transformación. Es decir, ni los que se refugian en la tradición viven totalmente anclados en el pasado sin relacionar a éste con el presente, ni los que rehúyen el concepto de tradición mantienen en un aislamiento aséptico sus aparentemente nuevas ideas. Comprendido así, el flujo continuo entre pasado, presente y futuro con la tradición aflorando y transformándose en cada uso de la misma, se puede entender mejor la búsqueda de regeneración, de restauración por parte de los actores de la historia.

Desde los inicios del siglo XIX podemos apreciar, tanto por parte de los defensores como de los detractores de las nuevas ideas políticas de soberanía nacional que empiezan a debatirse, la conciencia de estar viviendo un tiempo nuevo, aterrador e incluso apocalíptico en ciertos momentos para unos, ${ }^{21}$ cargado de ilusión y de promesas de cambio para otros. La forma de concebir el tiempo va a influir en la manera de reescribir la historia, y a su vez ésta va a reflejar el modelo de sociedad al que aspiran estos intelectuales al proyectar éstos al pasado las características políticas y sociales que desean para su presente y futuro. Se observa así un marcado entrelazamiento entre Tiempo, Historia y Política: de la manera de pensar el tiempo se deduce un tipo de reescritura de la historia y, dado el momento histórico de construcción de un nuevo modelo político, unas consecuencias en cuanto a las soluciones políticas propuestas. Podemos destacar así pues una interpretación bidireccional del tiempo (del presente-futuro hacia el pasado y viceversa) en la cual, a través de la reescritura de la historia, los intelectuales pondrán más el acento en unos cambios moderados 0 radicales de la realidad política y social: según el momento histórico y la tendencia ideológica considerada podemos apreciar toda una graduación de posibilidades.

El presente estudio se centra en el grupo de intelectuales que concibieron el tiempo como oportunidad (no exenta en ciertos momentos de temores, de avances y retrocesos, pero predominando la idea del ser humano como protagonista) y no como apocalipsis, por el interés que ofrecen las diferentes soluciones encontradas por sus autores a los problemas que planteaba esta nueva forma de concebir el tiempo. Esta elección no implica separar pensamiento tradicional y moderno pues, como hemos expresado en las páginas anteriores, éstos están fuertemente entrelazados. Sí supondrá valorar a los intelectuales en su conjunto, diferenciándoles principalmente en función de las soluciones que propusieron a los problemas que planteaba ver el tiempo y la historia bajo los ojos de un protagonismo humano.

\subsection{El tiempo como oportunidad}

El abismo experimentado en los inicios de la modernidad entre el espacio de experiencia y el horizonte de expectativas, implicó para parte de la intelectualidad ver de forma negativa el futuro desconocido, pero para otra parte supuso el considerarlo en términos positivos de riesgo y de oportunidad. La ficción de un "new beginning" que Aleida Assmann destaca frente a un origen mítico (el orden del mundo se situaría en este caso fuera del ser humano) en estos momentos iniciales de la modernidad, permitiría la experiencia y la construcción humana, el espíritu creador. ${ }^{22}$ Nuestro estudio se va a centrar en particular en los defensores de esta postura y en los problemas y soluciones que propusieron al enfrentarse al estudio de la historia, pues esa fase creadora no estuvo exenta de un cierto desasosiego intimo. Para Assmann este desasosiego se contrarrestaria al combinar "the 
SÁNCHEZ LEÓN, Pablo. Decadencia y Regeneración. La temporalidad en los conceptos fundamentales de la modernidad española. En: FERNÁNDEZ SEBASTIÁN, Javier; CAPELLÁN DE MIGUEL, Gonzalo (eds.). Lenguaje, tiempo y modernidad. Ensayos de historia conceptual. Santiago de Chile: Globo, 2011. p.81-111.

26

De ARGÜELLES ÁlVAREZ, Agustín En: Diario de Sesiones de las Cortes Generales y Extraordinarias, 12/9/1811. Madrid: Imprenta de J. A. García, 1870-1874, n.345. p.1826-1827.

27

GORDILLO y RAMOS, Pedro José. En: Diario de Sesiones de las Cortes Generales y Extraordinarias, 26/6/1811. Op. Cit., n.267. p.1338.

\section{8}

FERNÁNDEZ GASCÓ, Francisco. En: Diario de Sesiones de las Cortes Generales y Extraordinarias, 28/7/1820. Op. Cit., n.24. p.296.

29

REY ESTEVE, Joaquín. En: Diario de Sesiones de las Cortes Generales y Extraordinarias, 28/3/1821. Op. Cit., n.31. p.741.

30

GONZALO MORÓN, Fermín. Reflexiones sobre la Historia, 7 de marzo de 1841. En:___aut.) Curso de Historia de la civilización de España. Lecciones pronunciadas en el liceo de Valencia y en el Ateneo de Madrid en los cursos de 1840 y 1841. Madrid: Establecimiento Tipográfico Calle del Sordo n.11, 1841. p.56. fast life of progress and the slow life of tradition". "Humans develop and cherish a culture of preservation and memory in order to compensate for the frustrations of the modern world of progress".23 Rüsen considera a su vez que las formas tradicionales del pensamiento subyacen en todo pensamiento histórico así como en la identidad de los sujetos en cuanto que ésta incorpora sus condiciones de vida así como sus deseos, esperanzas y miedos: "tradition is a part of subjectivity and such it is an integral part of human identity". ${ }^{24}$ Este pensamiento tradicional no impediria llevar a cabo innovaciones o un juicio crítico sobre el pasado: ese pensamiento tendría diferentes formas de expresarse, más tradicionales o ejemplarizantes, o más críticas.

Los intelectuales partidarios de esta visión del tiempo arrancan de los presupuestos ilustrados de confianza en el progreso y así, pues, en el futuro. Estos autores son conscientes de que viven un tiempo nuevo y que éste debe de regirse por pautas diferentes de las que han existido hasta el momento. Lo antiguo debe reformarse, adaptarse o cambiarse totalmente para hacerlo compatible con los tiempos actuales lo cual lleva implícito, o favorece, la historicidad del tiempo histórico. Esta interpretación de tiempo nuevo y progreso lleva aparejada en España en particular, aspecto que la historiografía no ha destacado lo suficiente ${ }_{1}^{25}$ una noción de regeneración moral. El concepto de regeneración podría interpretarse como una mirada y una interpretación del pasado que aparentemente limitaría la "modernidad" del progreso deseado; en realidad no es así. En las páginas siguientes mostraremos la vinculación entre Historia, Progreso y Regeneración moral.

Para los defensores de esta postura, el pasado puede ser respetado, como lo son las personas ancianas, pero no por ello debe de ser trasplantado al presente: "La antigüedad no hace respetables los absurdos, no consagra los errores." ${ }^{26}$ No hay una negación o rechazo de los valores tradicionales, sino un intento de separación de estos valores de las prácticas de gobierno. Pero como afirma el diputado Gordillo en las Cortes, "por desgracia respetamos demasiado las instituciones que han sido autorizadas por el transcurso de los siglos"27, lo cual dificulta la toma de decisiones en un sentido reformista 0 rupturista. Es decir para estos intelectuales empieza a no ser incompatible la defensa de cambios drásticos en los principios políticos, incluidos cambios en la institución religiosa, con una defensa de valores tradicionales y religiosos. Pero a partir de la década de 1840, entre parte del liberalismo más moderado, se dará una cierta supeditación de la política a la religión uniéndose elementos de la esfera privada con la pública.

La conciencia de historicidad de las épocas, expresada tímidamente a finales del siglo XVIII, es ya clara en los inicios del siglo XIX: "Nuestras costumbres han variado; no vivimos en los tenebrosos siglos de la Edad Media; la opinión ha cambiado". ${ }^{28}$ Conciencia que no impide valorar las obras realizadas en el pasado, pero en su contexto histórico: "Yo bien quisiera que se conociesen bien nuestros Códigos; no son bárbaros, como se dice con sobrada ligereza; son el monumento de la sabiduría de los tiempos en que se hicieron y de sus autores, por más que algunas de sus disposiciones no sean aplicables al actual estado de la sociedad." ${ }^{29}$ Asímismo entender lo sucedido en los siglos anteriores debería servir para no cometer errores pasados; esto no implica entender la historia como "historia magistra vitae": "lo pasado ha muerto, ha mostrado con ello su imperfección" pero "lo pasado contiene la explicación de lo presente y puede suministrar excelentes indicaciones para lo sucesivo". ${ }^{30}$ La conciencia de la situación desastrosa en la que se encontraba España a finales del siglo XVIII y la confianza en 
31

FERNÁNDEZ SEBASTIÁN, Javier. Progreso. En: ; FUENTES, Juan Francisco (eds). Op.

Cit., p.562-575. Este autor ha desarrollado ampliamente el concepto de progreso por lo que en este apartado nos limitaremos a dar algunos apuntes centrados en particular en la idea de progreso de la humanidad.

PALTI, Elías José. Koselleck y la idea de Sattelzeit. Un debate sobre modernidad y temporalidad. Ayer, Madrid, n.53, p.69-70, 1 semestre 2004. el progreso facilitaron el desarrollo de la temporalización de la historia así como su vinculación con el concepto de regeneración.

En los discursos políticos o periodísticos los publicistas, frecuentemente, se remiten al pasado en busca de una continuidad, de unos ejemplos, del origen de una institución o de una práctica; pero, al mismo tiempo, tienden a distanciarse del pasado, denominando a ciertas épocas "tiempos bárbaros" o "tiempos despóticos", y a marcar la idea de progreso y de nuevos tiempos que supone el siglo XIX. La clave para entender la aparente contradicción entre búsqueda de continuidad y conciencia de tiempo nuevo, es que sobre ese pasado se van a proyectar las esperanzas e ilusiones del presente y del futuro, modificando el contenido y el significado de ese pasado. El pasado va a servir para proyectar en él los deseos de construcción de la nueva sociedad: es decir se va a recrear en el pasado las características de la nueva sociedad a construir. Muchos autores de la época, sobre todo a partir de la década de 1830, criticarán el anacronismo en el que según ellos habrían caído autores anteriores al atribuir principios imposibles a determinadas épocas. Pero todos ellos caen, a nuestros ojos, en esa especie de anacronismo. A pesar de ello, debemos considerar a ese anacronismo como parcial, limitado, "utópico" en el sentido de que solo recrean en el pasado el principio político que defienden, no realizan una visión anacrónica global de la sociedad pues defienden la historicidad de las épocas.

\section{Una nueva forma de pensar la historia}

\subsection{Sentido de la historia}

Podemos apreciar dos niveles interpretativos interconectados al sentido que le dieron los intelectuales a la historia desde finales del siglo XVIII y a lo largo del siglo XIX: uno más profundo que busca en la historia la manera de comprender el progreso humano y otro más "en la superficie" que busca una finalidad práctica. En el primer caso nos encontraremos con una evolución en la manera de concebirlo: si en época ilustrada se basaría en los avances científicos, a partir del tercer decenio del siglo XIX se basará en la conjugación de aspectos morales y materiales. En el segundo caso, esa finalidad práctica se sustentará en que la historia debía ayudar a la regeneración moral, a la recuperación del prestigio internacional, y en las luchas políticas para recrear en el pasado lo que se deseaba en el presente $y$ en el futuro.

\subsubsection{Historia y progreso de la humanidad ${ }^{31}$}

Desde finales de la llustración, algunos intelectuales empiezan a ser conscientes de la necesidad de realizar una historia total o historia de la civilización, aunque en este caso subyace la idea de globalidad de la humanidad. Así lo apunta Elías Palti: "La idea del "progreso histórico" como acumulación de saber entrañaba, en efecto, una asimetría entre "espacio de experiencia" y "horizonte de expectativa", pero al mismo tiempo suponía la existencia de una continuidad esencial, esto es, "una naturaleza humana" homogénea que le sirve de sustrato unitario a dicho proceso." ${ }^{32}$

$Y$ de aqui que cobre sentido el paso de una historia como rerum gestarum (narración de hechos) a una historia como res gestae (todas las vicisitudes de la especie humana). Así lo expone el periódico liberal El Censor en 1821: "Esto significa que si bien la ilustración, los usos, las costumbres y el gobierno de las naciones varian de un siglo a otro, y no son idénticos en todos los países, el fondo esencial de la naturaleza humana es uno mismo 
Utilidad de la Historia. El Censor, Madrid, 24/11/1821, n.69, p.188.

34

DE JOVELLANOS, Gaspar Melchor. Discurso leído por el autor en su recepción a la Real Academia de la Historia sobre la necesidad de unir al estudio de la legislación el de nuestra historia y antigüedades [4/2/1780]. En: NOCEDAL Cándido (org.). Obras publicadas e inéditas. Tomo I. Madrid: M. Rivadeneyra Impresor, editor, 1858. p.298.

35

FORNER, Juan Pablo. Reflexiones sobre el modo de escribir la Historia de España [c. 1788]. Madrid: imprenta de burgos, edición de 1816. p.63; también p.97.

36

Ibidem, p.63-64

37

GONZALO MORÓN, Fermín. Op. Cit., p.56.

38

Ibidem, p.18.

39

GIL DE ZARATE, Antonio. Introducción a la Historia moderna o Examen de los diferentes elementos que han entrado a constituir la civilización de los actuales pueblos europeos. Madrid: imprenta de Repullés, 1841. p.7.

40

DE ZARAG0ZA, José. Discurso leído en la recepción a la Real Academia de la Historia el 12 Abril de 1852. En: Discursos leídos en las Sesiones públicas que para dar posesión de plazas de número ha celebrado desde 1852 la Real Academia de la Historia. Madrid: Imprenta de los señores Matute y Compagni, 1858. p.6. en todos sus individuos, cualesquiera que sean por otra parte las modificaciones variables que se observan en ellos, debidas al clima, la educación y las instituciones políticas..." ${ }^{33}$

Por ello desde finales del siglo XVIII, el objeto de la historia empezó a cambiar entre algunos historiadores, pasando de ser los reyes y sus batallas a ser una historia de la sociedad humana en su conjunto: "Las crónicas, anales, historias solo comprenden cosas inútiles como guerras, batallas, conmociones, hambres, supersticiones. Falta una historia civil que explique el origen, progresos y alteraciones de nuestra constitución, nuestra jerarquía política y civil, nuestra legislación, nuestras costumbres, nuestras glorias y nuestras miserias." ${ }^{34} \mathrm{~A}$ pesar de ello en estos primeros momentos, el interés en la historia estuvo más centrado en una historia política con vistas a hacer progresar a la sociedad española: este tipo de historia permitiría "instruir a los hombres públicos en lo que deben saber, a fin de que conozcan el estado e interés de su patria y de las ajenas, según conviene al desempeño de sus cargos". ${ }^{35}$ La historia, sobre todo, debía de ayudar a entender la idea de progreso sobre la que se basaba toda la filosofía ilustrada y que serviria para entender la historia política: "La historia de la religión, de la legislación, de la economía interior, de la navegación, del comercio, de las ciencias y artes, de las mudanzas y turbulencias intestinas, de las relaciones con los demás pueblos, de los usos y modo de pensar de estos en diferentes tiempos, de las costumbres e inclinaciones de los monarcas, de sus guerras, pérdidas y conquistas, y del influjo que en diversas épocas tiene todo este cúmulo de cosas en la prosperidad de las sociedades civiles, es propiamente y debe ser la historia de las naciones." ${ }^{36}$

Para autores posteriores, en los que se aprecia una mayor influencia de François Guizot y de su teoría de la civilización, seguirá estando vigente la idea de una historia de la humanidad. Así para Fermín Gonzalo Morón la civilización es obra "de los esfuerzos intelectuales por comprender la naturaleza humana en su abstracción y en su desarrollo histórico". ${ }^{37}$ Para este autor se debió a Vico (y a su obra Scienza Nuova, 1725) el renacimiento de los estudios históricos, "la conciliación y doble estudio de los hechos y de las teorías y el examen del mundo moral y político [...] y quizá también se la deba un día el descubrimiento de los principios o leyes morales por que la humanidad debe ser gobernada". 38

Con el desarrollo progresivo del Estado moderno a partir de 1830, la historia pasará a tener objetivos políticos más amplios. Así, Antonio Gil de Zárate constatará que el estudio de la historia había dejado de ser solo para eruditos, pasando a ser "una necesidad para el ciudadano que quiere tener parte en los negocios de su patria, o cuando menos, juzgar de ellos con acierto".39 Es decir, la historia debía de servir para formar buenos ciudadanos. Por su parte, el académico de la historia José de Zaragoza, destacará que, dados los tiempos y el protagonismo de las diferentes clases sociales en el gobierno del Estado, la historia ya no debía de servir como guía para la educación de los reyes sino que debía de servir (y escribirse) para todos. Por ello un estudio histórico debía de ser capaz de pintar, a lo largo de los siglos, la variedad de "un pueblo con sus ideas y sus instintos, con sus aciertos y sus errores, con la infinita variedad de sus formas, costumbres y opiniones".40 Subrayaba así el cambio de objeto de estudio de la historia, de los reyes al pueblo en su totalidad.

Este nuevo enfoque a su vez favorecerá el desarrollo de la novela histórica o costumbrista. Asi se expresaba Benito Pérez Galdós en el Prólogo a 
41

PÉREZ GALDÓS, Benito. Al lector (Segundo prólogo a la edición ilustrada, 1885). En: (aut.). Episodios nacionales. Primera serie. La guerra de la Independencia. Barcelona: Destino, 2005. p.26.

42

La crisis de conciencia que empezaron a experimentar los ilustrados y que continuará en los decenios siguientes ya fue advertida por LÓPEZ, François. Juan Pablo Forner et la crise de la conscience espagnole au XVIIle siècle. Bordeaux: Institut d'Études lbériques et Ibéro-américaines de I'Université de Bordeaux, 1976. p.432 o por STIFFONI, Giovanni. Verità della Storia e ragioni del potere nella Spagna del primo '700. Milano: Franco Angeli, 1989. p.162.

43

"A "cultural pattern" may be defined as the connection of concepts and practices which have gained a relative perpetuity through cultural habitualization. Cultural patterns include a combination of interpretative schemes according to which the world can be categorized, structured and interpreted with individual or social practices which either develop out of, or follow these schemes": FULDA, Daniel. Historicism as a cultural pattern: practising a mode of thought. Journal of the Philosophy of History, Leiden, n.4, p.138-153, 1 semestre 2010.

44

GONZÁLEZ MANSO, Ana Isabel. Asymmetrical Concepts in the re-writing of history in Spanish liberalism at the beginning of the nineteenth century. En: POSTOUTENKO, Kirill (ed.). Capitulo de un libro de próxima aparición.

45

KOSELLECK, Reinhart. Progreso y decadencia. Apéndice sobre la historia de dos conceptos. En: (aut.). Historias de conceptos. Estudios sobre semántica y pragmática del lenguaje político y social. Madrid: Trotta, 2012. p.95-112. su magna obra de los Episodios Nacionales: "Lo que comúnmente se llama Historia, es decir, los abultados libros en que sólo se trata de casamientos de reyes y príncipes, de tratados y alianzas, de las campañas de mar y tierra, dejando en olvido todo lo demás que constituye la existencia de los pueblos, no bastaba para fundamento de estas relaciones, que o no son nada, o son el vivir, el sentir y hasta el respirar de la gente." ${ }^{41}$

\subsubsection{Historia y regeneración moral}

Si desde finales del siglo XVIII predomina la idea de progreso humano a lo largo de la historia, ¿cómo explicar la situación concreta de España en los últimos siglos?, se plantearon los intelectuales del momento. Por ello, desde la época ilustrada, se dio por parte de los intelectuales-políticos, la reivindicación de un pasado glorioso de España que querían recuperar, una explicación de la degeneración sufrida y una propuesta de solución que pasase principalmente por la regeneración moral de la sociedad..$^{42}$ Este deseo de regeneración es el "cultural pattern" subyacente a las decisiones políticas. ${ }^{43}$

Existe una fuerte relación entre los conceptos de degeneración y de progreso, conceptos que podrían ser considerados como asimétricos. ${ }^{44} \mathrm{La}$ noción de progreso, característico de la modernidad y que conlleva la ruptura entre el espacio de experiencia y el horizonte de expectativa, entraña, tal y como ya apuntaba Koselleck, una aporia: a más progreso más posibilidades de decadencia y de desfase entre progreso técnico y comportamiento moral. ${ }^{45}$ En el marco español de finales del siglo XVIII se aprecia una variante en esta relación de conceptos: progreso implicará regeneración moral o, dicho de otro modo, sólo puede darse progreso en un marco moral. Primero los ilustrados y posteriormente el mundo liberal, consciente de la aceleración de los tiempos, intentarán vincular progreso con regeneración moral recurriendo a una relectura del pasado que demostrase que ambos conceptos habian sido necesarios en los siglos anteriores y debian serlo en el presente.

Ya desde el siglo XVIII se observa por parte de los ilustrados la conciencia de atraso de España, de pérdida de prestigio frente al resto de los países europeos. El tema del retraso español frente a las demás naciones europeas, tratado ya desde el siglo XVII y más intensamente en el XVIII, se había convertido para los españoles de los inicios del siglo XIX en una realidad humillante. Esta toma de conciencia del estado en el que se encontraba España va a conllevar principalmente tres reacciones interconectadas: en primer lugar un diagnóstico de la causa de la decadencia; en segundo lugar, y como consecuencia de esa valoración, la vinculación de regeneración moral con progreso $y$, finalmente, una relectura del pasado en la cual los intelectuales van a poner de relieve los periodos de la historia en los que, según ellos, predominaron en España valores morales, viéndose esta situación acompañada de prestigio y de progreso de la nación frente al resto de los paises europeos. La conclusión a la que llegaron los intelectuales ilustrados y los primeros liberales fue que la decadencia española habría estado motivada por la contaminación de formas de gobierno venidas de fuera que habrían provocado una degeneración de las "sanas costumbres" españolas. Se imponía entonces una regeneración moral de la sociedad para poder hacer frente a los nuevos retos que representaban el presente y el futuro. Para poder iniciar esta andadura en paridad de condiciones con el resto de los paises del entorno, estos intelectuales necesitaron enlazar con la parte del pasado en la que consideraban que España había demostrado estar por delante del resto de los países europeos. 
46

Discurso del presbitero D. Miguel Cabral de Noroña el 9/11/1812 en casa del Sr. D. Luis de Onis en Filadelfia con motivo de la jura de la Constitución sancionada en Cádiz por parte de los patriotas españoles. El Tribuno del Pueblo Español, Cádiz, 17/11/1812, n.5, p.57.

47

MARTÍNEZ MARINA, Francisco. Discurso sobre el origen de la monarquía y sobre la naturaleza del gobierno español [1811]. Madrid: Centro de Estudios Constitucionales, 1988. p.159.

48

FERNÁNDEZ TORRES, Luis. El concepto de interés en España, 1770-1823. Historiografías, Zaragoza, n.7, p.34-54, enero-junio 2014. Disponible en: <http://www.unizar.es/historiografias/numeros/7/ fernandez_res.pdf>. Acceso: 01 ago. 2015.

49

FERNÁNDEZ SEBASTIÁN, Javier. A Distorting Mirror: The Sixteenth Century in the Historical Imagination of the First Hispanic Liberals. History of European Ideas, Londres, 2014. Disponible en: $<$ http://dx.doi.org/10.1080/01916599.2014.914 309>. Acceso: 01 ago. 2015. En este artículo su autor destaca la mirada crítica de los liberales decimonónicos al siglo XVI español para poder enlazar con la visión de progreso imperante en la Europa del momento.

50

GUERRA, François-Xavier. Modernidad e independencias. Ensayos sobre las revoluciones hispánicas. México: FCE, 2000.
Es decir vincularon regeneración moral a progreso en el pasado, para así poder hacerlo en su presente. Por ello también, los intelectuales llevaron a cabo una relectura del pasado en la que pusieron de manifiesto la neta oposición entre España y el resto de Europa.

Así autores ilustrados como Jovellanos, Capmany o Sempere y Guarinos intentaron contrarrestar esta sensación de desprestigio reescribiendo la historia civil nacional. Esa historia, además de seguir los criterios de crítica y análisis racional basado en documentación, buscaba reconstruir los motivos y las causas de la evolución de España y en particular de su decadencia. Para los intelectuales de finales del siglo XVIII e inicios del siglo XIX, la crisis que sufría España era de tipo moral, de valores. La idea de que España era una sombra de lo que fue queda expresada en el periódico liberal El Tribuno del Pueblo Español: "No parecía ya ni la sombra de aquel pueblo grande ante quien se estrellaron las olas del poder romano, y que, atrincherado en las sierras Cantábricas, resistió a la inundación espantosa de los árabes, y los arrojó con la sola pujanza de su brazo a las arenas del África; que inmortalizó el nombre godo con victorias y virtudes sublimes; que dio la ley al mundo bajo los primeros príncipes de la dinastía austriaca." ${ }^{46} 0$ por Francisco Martínez Marina, historiador-político cuyo influjo fue notable en la redacción de la Constitución de 1812: "Hoy más que nunca debemos ocuparnos en el estudio de la filosofía y de la moral pública [...]. Hoy más que nunca estamos obligados en calidad de hombres y de ciudadanos a meditar con toda la energía de que es capaz nuestro espíritu sobre los principios y causas de la ruina y destrucción de los grandes imperios como de su gloria y prosperidad." ${ }^{47}$

Este acento en los valores permitía salvar el escollo que suponian una serie de hechos y circunstancias donde los españoles habian quedado desprestigiados. Aunque los fisiócratas habían insistido en los aspectos económicos, la reivindicación constante de regeneración, presente en los autores españoles decimonónicos, no fue directamente de tipo económico; era un aspecto que con la regeneración moral y política se conseguiría implícitamente. ${ }^{48}$ Por ello, en ese afán de reescritura de la historia, el principal interés no se centró en los siglos de mayor esplendor de España, la época de los Austrias, sino que se puso en un periodo anterior. ${ }^{49}$ Además de buscar elementos de construcción nacional (más evidentes según avance el siglo XIX), como ya apuntaron autores como François-Xavier Guerra, ${ }^{50}$ estos intelectuales buscaron en tiempos más remotos elementos de dignidad moral que recuperar. Esa regeneración moral, que había permitido el esplendor de España en el pasado, era imprescindible para poder afrontar el futuro y sobre todo para poder hacer progresar al país. Para los ilustrados y liberales, si en el pasado, cuando España manifestó claros rasgos de dignidad moral, se había encontrado a la vanguardia de Europa, ahora, en los inicios del siglo XIX, debía de producirse la misma situación: la regeneración moral equivalía a la posibilidad de progresar en todos los campos, científicos, literarios o políticos.

Los intelectuales de finales del siglo XVIII e inicios del siglo XIX intentaron además de manera constante, mostrar al resto del mundo que España merecía estar entre las naciones más importantes porque desde los primeros siglos de nuestra era había manifestado virtudes y valores que se plasmaron en su forma de gobierno.

Uno de los principales motivos que tuvieron los ilustrados para reescribir la historia nacional fue poder darla a conocer fuera de sus fron- 
FEYJÓO Y MONTENEGRO, Fr. Benito Jerónimo. Reflexiones sobre la Historia. En:__ (aut.). Teatro Crítico Universal o Discursos varios en todo género de materias para desengaño de errores comunes. Tomo IV. Madrid: Joaquín Ibarra Impresor de Cámara de S.M., edición de 1769. p.149-224. teras y poder mostrar que España merecía ser reconocida por sus méritos pasados. España tenía unas bases que sustentaban sus reclamaciones de prestigio y al mismo tiempo (en el caso liberal) unas bases sobre las que apoyar la construcción del nuevo edifico político. No necesitaba seguir los modelos extranjeros. A pesar de que el mundo liberal rechazó "retóricamente" el modelo constitucional francés de 1791, éste será la base para la Constitución gaditana de 1812, eso sí presentado y adaptado al caso español enlazándolo con su pasado y sobre todo con las características del ser español.. Por todo ello, junto a la reclamación de reconocimiento de un pasado glorioso, hay un intento de explicación de la situación de España que pasa por la falta de valoración de sus méritos pasados así como por las interferencias de elementos extranjeros que habrian perturbado las esencias españolas. Una manera de restablecer el prestigio pasado será a través de los códigos, reflejos estos a su vez de las costumbres y valores de los españoles: estariamos ante el "espíritu de las leyes" de Montesquieu. Estos códigos, interpretados en clave liberal, serían la muestra del pasado glorioso español; interpretados en clave no liberal, servirian para defender la continuidad de las viejas instituciones.

La continuidad histórica cobraría en este caso un significado diferente del tradicionalmente dado de rastrear las raíces de la nación o las bases para la nueva Constitución liberal. Los diferentes autores no van a poner el acento en momentos históricos de gran prestigio económico sino en momentos de mayor prestigio cultural, social y sobre todo moral. Primero los ilustrados y después los liberales, coincidirán en las causas del decaimiento de España: la influencia extranjera y, como consecuencia, la degeneración de la moral y de las costumbres genuinamente hispanas. Esta degeneración se habria iniciado a mediados del siglo XII y más claramente a partir del gobierno de la dinastía austriaca (siglo XVI) aunque también, en particular durante la Guerra de la Independencia contra Francia, manifestarán su descontento por la entrada de las ideas venidas del país vecino. ${ }^{51}$ La solución propuesta a esta situación será la regeneración moral: para el mundo liberal los tres siglos de despotismo, del XVI al XVIII, habrian traido la corrupción de las costumbres, así que había que recobrar y restaurar los valores perdidos. Esta solución llevará a los intelectuales a realizar una relectura del pasado proyectando en él los deseos de reforma y cambio que desean para su presente y futuro: es decir verán elementos de los nuevos conceptos políticos manejados en épocas remotas como la Edad Media.

\subsection{Historicismo}

Autores ilustrados como Fr. Benito Feijoo empezaron a tomar conciencia de la historicidad de las épocas; por ello aplicarán un criterio crítico al conocimiento de los datos para ver si eran coherentes con las épocas a las que correspondían así como para conocer estas mismas informaciones de otras naciones pues los sucesos se influían mutuamente. ${ }^{52}$ En realidad los historiadores empiezan a tomar conciencia de la temporalización de la historia en pro del objetivo práctico de conocer mejor la sociedad de los hombres para así poder mejorarla.

A partir de la década de 1830, posiblemente por influencia del nuevo contexto cultural europeo, aumentarán las manifestaciones expresas de los autores de comprender cada época en su contexto. Pero al mismo tiempo los intelectuales empiezan a tomar conciencia de que los estudios históricos son un reflejo del pensamiento cultural de la época en la que 
De los diferentes modos de escribir la historia. El Eco del Comercio, Madrid, 29/12/1834, n.243.

54

ALCALÁ GALIANO, Antonio. Lecciones de Derecho Político. Madrid: Centro de Estudios Constitucionales, 1984. p.22.

55

Ibidem, p.23

56

FERNÁNDEZ SEBASTIÁN, Javier. Tradiciones electivas. Cambio, continuidad y ruptura en historia intelectual. Almanack, Guarulhos, n.7, p.18, 1 semestre 2014.

57

Ibidem, p.18-19. el historiador escribe; la historia (el pasado) estaría inserta en el presente y a su servicio. Las preguntas que los intelectuales de mediados del siglo XIX plantearán al pasado, la manera de interpretarlo dependerán, según ellos, del momento cultural de cada sociedad: "suelen los pueblos considerar la historia bajo diferentes aspectos y buscar en ella diferente género de interés, según varía su situación política y el grado de civilización en que se hallan".53

Para autores como Antonio Alcalá Galiano, la historia es valiosa en cuanto que es un dato del pasado pero observable en el presente fundamentalmente a través de las tradiciones vivas y útiles: "En los hombres puede más lo heredado que lo adquirido, lo mamado con la leche que lo aprendido a fuerza de trabajo, de lectura, de meditaciones. En balde es que pretendamos reñir con lo pasado." ${ }^{54}$ Este autor, para ilustrar la permanencia a nivel de nuestro subconsciente de las costumbres pasadas, utiliza el ejemplo de un cartel que se podia leer en Francia en una oficina en tiempos del Terror: en grandes letras aparecía sobre la puerta: "Aquí se tutea todo el mundo", y más adelante, obedeciendo a los antiguos usos y costumbres, había otro letrero que decía: "Se suplica a V. que se limpie los pies y se quite el sombrero". 55

Javier Fernández Sebastián ha propuesto recientemente, y completando los tres modelos de tradición propuestos por Rüsen, un cuarto modelo que ha denominado tradición electiva: más que una herencia recibida de las generaciones anteriores sería un legado histórico imaginado y elaborado por el propio legatario. "De entre todos los pasados posibles, cada actor colectivo selecciona de acuerdo con sus preferencias aquellos hechos, autores o episodios históricos en los que de algún modo se reconoce: aquellos que mejor se adaptan a sus necesidades de legitimación y a sus perspectivas de futuro". ${ }^{16}$ No se trataria de las tradiciones inventadas de Hobsbawm pues esas tradiciones existirian ya aunque con significados diferentes de los que se les quiere atribuir. Se estaría produciendo una íntima relación entre la recepción pasiva de las tradiciones, la transformación de las mismas en ese proceso de recepción y la elección activa de las tradiciones más acordes al objetivo buscado. Estas tradiciones "son perfiladas para dotar retrospectivamente a tal o cual concepto, a tal o cual grupo o movimiento, a tal o cual ideología, de un pasado ad hoc especialmente diseñado para dar verosimilitud a las expectativas de futuro que parecen desprenderse naturalmente de ese pasado.".57 Este cuarto modelo de tradición supone para su autor, poner el acento en el aspecto voluntario y así pues utilitarista de las tradiciones para legitimar las ideologías defendidas en un determinado momento; por nuestra parte lo que apreciamos a inicios del siglo XIX es que estas tradiciones son "sentidas" por los intelectuales como algo propio aunque ellos les estén dando un significado totalmente nuevo. Esta resemantización de las tradiciones políticas no supone forzar su significado por extraño que pueda parecer a los ojos del historiador moderno.

\subsection{Historiografía y reflexiones metodológicas}

El descubrimiento de un mundo histórico y la diferenciación cualitativa entre pasado, presente y futuro, van a tener importantes implicaciones metodológicas para la historiografía: además de permitir desarrollar un método histórico propio, implicará el considerar la distancia a los acontecimientos como clave para conseguir la imparcialidad y la objetividad.

Las reflexiones historicistas llevaron a planteamientos de orden historiográfico donde se criticará y analizará la obra de pensadores anteriores 
58

MARTINEZ DE LA ROSA, Francisco. ¿Cuál es el método o sistema preferible para escribir la historia? Tomo I. Revista de Madrid, segunda serie. Madrid: Oficina de D. Tomás Jordán, 1839. p.535; en el mismo sentido GIL DE ZARATE, Antonio. Op. Cit., p.3.

59

DE PIDAL, Marqués (Pedro José Pidal). Lecciones sobre la historia del gobierno y legislación de España (desde los tiempos primitivos hasta la Reconquista), pronunciadas en el Ateneo de Madrid en los años 1841 y 1842. Madrid: imprenta de la Revista de Legislación, 1880. p.9.

60

MARTÍNEZ DE LA ROSA, Francisco. ¿Cuál es el método o sistema preferible para escribir la historia?. Op. Cit., p.535. de acuerdo a la premisa de que sus obras son producto de una época. Si ilustrados como Jovellanos, Feijoo o Madeus criticaron la historia realizada por historiadores de siglos anteriores como Mariana, Zurita or caer frecuentemente en la credulidad en fábulas, autores decimonónicos como Martínez de la Rosa o Gonzalo Moróncriticarán la obra de historiadores del siglo XVIII por caer en la abstracción filosófica. Nos encontramos ya en la década de 1830, en un periodo donde los principios románticos así como las nuevas ideas doctrinarias francesas y empiristas inglesas empiezan a tener un influjo claro en España. A pesar de la persistencia entre los liberales progresistas, cada vez menos frecuente sin embargo, de dejarse llevar por principios abstractos para defender sus reformas políticas, por lo general el liberalismo adhirió al anclaje de sus propuestas en realidades sociales concretas. Los ideales abstractos ilustrados tenían la ventaja de poder establecer una vinculación con los principios iusnaturalistas y de derechos naturales que podían ser interpretados en clave religiosa. Al renunciar a estos principios, los intelectuales del momento empezaron a sentir el desasosiego de un vacío que llenarán con la religión entendida en algunos casos, de una manera un tanto "integrista".

En la crítica a la abstracción filosófica, Francisco Martínez de la Rosa consideró que en el siglo XVIII, esta abstracción había impregnado la manera de pensar la historia: "El vicio capital a que está expuesto ese método de escribir la historia consiste en que, lejos de conducir al camino más natural, examinando los hechos y deduciendo de ellos las consecuencias que de sí arrojen, inclina a seguir un rumbo opuesto; formando el autor de antemano lo que puede llamarse Su sistema, y amoldando a él los hechos, violentándolos a veces para que vengan a la justa medida..." ${ }^{58}$ Por ello, este autor defenderá una historia que fuese al fondo de las ideas y a la realidad de las cosas, huyendo de una historia filosófica de sistemas y de verdades abstractas y centrándose en suministrar "datos útiles y procurar ventajas efectivas".

Pedro José Pidal (marqués de Pidal) verá incluso un acto deliberado de falsificación de la historia el intentar adaptar los hechos pasados a unas teorías filosóficas: "¿Quién ve ya hoy, por ejemplo, la historia de la edad media, la de su civilización, empresas y afecciones, bajo el mismo punto de vista en que la vio la falsa filosofía del siglo pasado? ¿Quién considera ya del mismo modo la grande y civilizadora influencia del Cristianismo y de la Iglesia? ¿Quién el fecundo y progresivo principio de la unidad social, que lleva en su seno la magnífica institución de la monarquía? Y finalmente, señores ¿quién no reconoce ya y confiesa en la actualidad que entonces, en el siglo pasado, se cometió una grande falsificación histórica, queriendo violentar los hechos de la humanidad en toda su dilatada e inmensa carrera, para forzarlos a que viniesen a servir de prueba y confirmación a una filosofía...?"59

También serán objeto de críticas por parte de los autores antes mencionados, las obras de casi coetáneos suyos, en particular Martínez Marina o Sempere y Guarinos, por apreciar en ellas una adaptación de los hechos a sus teorias y por utilizar la historia como arma en la lucha política. Así Martínez de la Rosa criticando a Martínez Marina afirmará: "presentó los hechos y datos bajo el aspecto que convenía al fin político que se había propuesto, aun cuando fuese a costa de la exactitud".60 Este tipo de historia es según Martínez de la Rosa la consecuencia de ajustar unos hechos a un sistema filosófico. Gonzalo Morón también destaca el que Martínez Marina habría puesto al servicio de sus ideales políticos la reescritura de la histo- 
61

GONZALO MORÓN, Fermín. Op. Cit., p.45.

62

ALCALÁ GALIANO, Antonio. Discursos leídos ante la Real Academia de la Historia, en la recepción pública del 26 de diciembre de 1864. Madrid: Imprenta de José Rodríguez, 1864. p.9.

63

FEYJÓO Y MONTENEGRO, Fr. Benito Jerónimo. Reflexiones sobre la Historia. Op. Cit., p.223.

64

DE MASDEU, Juan Francisco. Prólogo. En: (aut.). Historia crítica de España y de la cultura española en todo género, [1783-1805]. Tomo I. Traducción de N.N. Madrid: Antonio de Sancha, edición de 1784. p.IX.

65

LAFUENTE Y ZAMALLOA, Modesto. Prólogo. En: (aut.) Historia General de España, desde los tiempos más remotos hasta nuestros días. Tomo I. Madrid: Establecimiento Tipográfico de Mellado, 1850. p.XXIV-XXV.

66

Ibidem, p.XXVI

MARTÍNEZ DE LA ROSA, Francisco. Contestación al discurso de Salustiano de Olózaga. En: Discursos leídos en las Sesiones públicas..., Op. Cit., p.146-147.

ria que llevó a cabo: "Sujetado los hechos a esta teoria [que España había tenido una constitución democrática hasta la dinastía de los Austrias], no distinguió tiempos, forzó inducciones, violentó palabras, mutiló textos, ofreció datos singulares en apoyo de un sistema general, y en su pluma la historia fue una verdadera máquina de guerra y reforma."61

Mientras Martínez de la Rosa criticaba a Martínez Marina por su adaptación de los hechos a un ideal filosófico, Alcalá Galiano le criticará por interpretar el pasado con los ojos de su presente. En realidad ambos le reprochan la proyección al pasado de los ideales presentes, proyección que estos autores también llevarán a cabo; el verdadero punto de discusión es que esos ideales ya no coinciden con los de Martínez Marina. Así mismo Alcalá Galiano criticará a Sempere por lo contrario, por sacrificar lo más antiguo a lo más moderno. ${ }^{62}$

La crítica historiográfica va a llevar aparejada, desde finales del siglo XVIII, consideraciones de tipo metodológico sobre cómo se debía de escribir la historia. Benito Feijoo presentó las cualidades que debía de tener un buen historiador a partir de las cuales podemos deducir los objetivos y las caracteristicas metodológicas de la práctica histórica: "Un amor grande a la verdad, a quién ningún respecto acobarde; un espiritu comprensivo, a quién la multitud de especies no confunda; un genio metódico, que las ordene; un juicio superior, que según sus méritos, las califique: un ingenio penetrante, que entre tantas apariencias encontradas, discierna las legítimas señas de la verdad de las adulterinas; y en fin un estilo noble y claro."63 Juan Francisco Masdeu menciona además la necesidad de citas frecuentes y la metodología de ponerlas a pie de página para que no dificulten la lectura, siguiendo criterios totalmente científicos. ${ }^{64}$

En 1850, Modesto Lafuente propuso como metodología histórica en su Historia General de España, obra que vino a sustituir como obra de referencia histórica a la Historia de Mariana (que seguía vigente desde finales del siglo XVI en que fue escrita y que tuvo numerosas ediciones hasta mediados del siglo XIX), "estudiar los hechos, y consecuentemente ver si los resultados de la experiencia confirman los principios y si estos explican aquellos". Pero todo ello con la mayor claridad posible, por lo cual no "interpondrá largas distancias entre la relación y las reflexiones" para evitar que "si los resultados morales o políticos se separaran tanto de los hechos [que] el lector no pudiera ligarlos sin poner en tortura su memoria, o sin obligarle a hacer una nueva lectura de los sucesos".65 Cuestionó la división en épocas o edades de la historia pues "los periodos de tiempo en que puede dividirse la historia son por lo regular tan imperfectos como las divisiones que solemos hacer del espacio, porque todo se encadena en uno y otro por gradaciones insensibles". 66 Estamos ante una historia concebida como producto de una concatenación de hechos, los actuales dependientes de los anteriores, donde no se aprecian rupturas bruscas y con un presente considerado consecuencia de un pasado.

Asimismo ciertos autores como Martínez de la Rosa se plantearan, al hacer presente el pasado, el riesgo de caer en el anacronismo: "Más al propio tiempo es necesario, si no se quiere dar margen a gravísimos inconvenientes, considerar los hechos pasados con relación a su tiempo y a sus circunstancias, y no cometer una especie de anacronismo juzgándolos con nuestras preocupaciones." ${ }^{\text {67 }}$ Alcalá Galiano también reprocha a Martínez Marina en su obra Teoría de las Cortes, un cierto anacronismo, aunque sin mencionarlo expresamente, al considerar que este autor atribuía a la Edad 
ALCALÁ GALIANO, Antonio. Discursos leídos en las Sesiones públicas..., Op. Cit., p.9.

69

FEYJÓO Y MONTENEGRO, Fr. Benito Jerónimo. Reflexiones sobre la Historia. Op. Cit., p.164.

70

FEYJÓO Y MONTENEGRO, Fr. Benito Jerónimo. Loc. Cit.

71

Idem. Argumentos de Autoridad. En:__ (aut.). Teatro Crítico Universal o Discursos varios en todo género de materias para desengaño de errores comunes. Tomo VIII. Madrid: Pedro Marín, edición de 1773. p.44; en el mismo sentido MASDEU, Juan Francisco. Op. Cit., p.VI.

72

SAN MIGUEL, Evaristo. Discurso de Recepción, 3 de abril de 1853. En: Discursos leídos en las Sesiones públicas..., Op. Cit., p.198.

73

LAFUENTE Y ZAMALLOA, Modesto. Op. Cit., p.III-IV.

74

Ibidem, p.XXXIII.

75

MENÉNDEZ Y PELAYO, Marcelino. Discurso preliminar a la primera edición (26/11/1877). En: (aut.). Historias de los heterodoxos..., 0p. Cit., p.67.
Media un grado de perfección imposible para la época "y en las leyes y costumbres y actos de la misma época, una índole propia solo de un periodo más ilustrado".68

Desde época ilustrada se advertirá del peligro de que la subjetividad del historiador quede plasmada en su obra. Así Feijoo constata "¿Quién puede comprender todos los afectos que hay en el corazón de un Escritor que no conoce, ni ha tratado? ¿Quién puede determinar a cuantos objetos se extienden, o su amor, o su odio?" ${ }^{69}$ Esos intereses, en muchos casos de tipo religioso o nacional, dan origen a falsedades que a fuerza de repetirlas adquieren autoridad: "Lo peor es que como cualquier libelo infamatorio contra los de opuesta Religión es fácilmente creído, luego se trasladan a las Historias las sátiras más infames y más inverosímiles: con que después se citan por una fábula quinientos Autores, los cuales, si se mira bien, no tienen más autoridad, que aquel libelo de donde se derivó a todos la noticia." ${ }^{" 70}$ De aquí la importancia de aplicar la razón frente al criterio de autoridad. ${ }^{71}$

En el mismo sentido, años más tarde, Evaristo San Miguel afirmará: "Porque, en medio de tanta ilustración, ¿quién prescinde siempre de sus propias ideas, de las impresiones de su primera juventud, del espíritu de secta, de partido, de las pasiones mismas que inspiran su lenguaje hasta en los acontecimientos más remotos que describe?"72 Estamos ya inmersos en pleno romanticismo.

Modesto Lafuente también abogará por la imparcialidad y el desapasionamiento como caracteristicas del buen historiador, caracteristicas que reconoce son más fáciles de lograr cuanta mayor distancia exista con los hechos narrados. ${ }^{73}$ Pero al mismo tiempo constata que la historia no puede ser una mera exposición aséptica de sucesos pues eso haría que perdiese su carácter moral: "Aun supuesta la más imparcial y exacta pintura de las acciones buenas o malas de los hombres, ¿bastaría esto para llenar los altos fines morales de la historia? Frialdad culpable parecería esta imparcialidad cuando se trata de pintar el vicio o la virtud, y así podría conducir al escepticismo en asuntos de religión, como al indiferentismo político en negocios que tocan al amor de la patria." ${ }^{174}$

Más contundente será años después Menéndez Pelayo, principal historiador español católico de finales del siglo XIX inicios del siglo XX: "[Una historia de la heterodoxia] no debe ser escrita con esa indiferencia que presume de imparcialidad, porque este criterio solo puede aplicarse (y con hartas dificultades) a una narración de hechos externos, de batallas, de negociaciones diplomáticas o de conquistas (y aun éstas, en sus efectos, no en sus causas): nunca a una historia de doctrinas y de libros, en que la crítica ha de decidirse necesariamente por el bien o por el mal, por la luz 0 por las tinieblas, por la verdad o por el error...Y desde el momento en que esto hace, pierde el escritor aquella imparcialidad estricta de que blasonan muchos y que muy pocos cumplen..."75

\subsection{La historia en las luchas políticas: la historia como tribunal} Ante un siglo XIX convulso, Modesto Lafuente apuntó al protagonismo de la filosofía política y de la acción política en la vida de toda sociedad. Si los historiadores anteriores habian proyectado la política en la historia pero sin todavía una conciencia clara de ello o enmascarada en muchos casos bajo la rúbrica de filosofía de la historia, con Lafuente se produjo un reconocimiento explícito de la entrada de la política en la historia. Uno de los primeros en apuntar la necesidad de que el estudio de la historia dejase de 
ARGÜELLES, Agustín. Discurso Preliminar a la Constitución de 1812. Cádiz 24 de Diciembre de 1811. Madrid: Centro de Estudios Constitucionales, 1989.

77

Esta constatación ya la realizó Guillermo Zermeño al hacer un balance del concepto de historia en el mundo iberoamericano de 1750 a 1850: ZERMEÑO PADILLA, Guillermo. Historia, experiencia y modernidad en Iberoamérica, 1750-1850. En: FERNÁNDEZ SEBASTIÁN, Javier (dir.). Diccionario político y social del mundo iberoamericano. La era de las revoluciones, 1750-1850. Madrid: Centro de Estudios Políticos y Constitucionales, 2009. p.551-579.

78

Política: Reflexiones. El Tribuno del Pueblo Español, Cádiz, 23/3/1813, n.42. p.255.

79

Este es solo uno de los numerosos ejemplos que podemos encontrar en este periódico: Constitución Española. El Universal, Madrid, 2/8/1821, n.214.

80

De los estados generales comparados con las cámaras representativas. El Censor, Madrid, 9/6/1821, p.161-185, n.45; Origen del liberalismo europeo. El Censor, Madrid, 31/3/1821, p.321341, n.35.

81

Origen, progresos y estado actual del sistema representativo en las naciones europeas. El Censor, Madrid, 5/8/1820, p.25-50, n.1.

82

BORRULL y VILANOVA, Francisco Javier. En: Diario de Sesiones de las Cortes Generales y Extraordinarias, 28/8/1811. Op. Cit., n.330, p.1711; VILLANUEVA y ASTENG0, Joaquín Lorenzo. En: Diario de Sesiones de las Cortes Generales y Extraordinarias, 12/10/1812. Op. Cit., n.677, p.3809.

83

POLO y CATALINA, Juan. En: Diario de Sesiones de las Cortes Generales y Extraordinarias, 11/6/1811. Op. Cit., n.253, p.1242.

84

CONDE DE TORENO (José María Queipo de Llano Ruíz de Saravia). En: Diario de Sesiones de las Cortes Generales y Extraordinarias, 16/1/1812. 0p. Cit., n.470, p.2634.

85

CORTÉS y LÓPEZ, Miguel. En: Diario de Sesiones de las Cortes Generales y Extraordinarias, 29/3/1821. Op. Cit., n.32, p.758.

86

FERNÁNDEZ GOLFÍN, Francisco. En: Diario de Sesiones de las Cortes Generales y Extraordinarias, 29/8/1811. Op. Cit., n.331, p.1721.

87

HARTOG, François. Croire en l'Histoire. París: Flammarion, 2013. En particular p.51-54. tener un carácter elitista y pasase a tener una finalidad práctica de aplicación política fue Agustín de Argüelles ya a la altura de $1811 .^{76}$

Podemos considerar que una de las finalidades de la historia a inicios del siglo XIX fue su función creadora de identidad, frente a las demás naciones y dentro de España, entre las diferentes tendencias ideológicas y de aquí su entrada en el campo de la política. A través de la recreación del pasado que realizará cada publicista se plasmarán sus ideales presentes y futuros y así pues su forma de concebir la construcción política del Estado moderno.

Los acontecimientos acaecidos en España a partir de 1808, con la entrada de las tropas de Napoleón, romperán la dinámica de una historia reflexiva iniciada por el mundo ilustrado, pasando a ser necesaria una historia más práctica, más ligada a los acontecimientos que estaban sucediendo. ${ }^{77}$ Pero esto no significó que la manera de hacer historia iniciada por los ilustrados quedara en el olvido: lo que se hizo fue aplicar los criterios establecidos pero adaptándolos a las necesidades políticas del momento.

Desde los inicios del siglo XIX cualquier artículo, cualquier intervención parlamentaria se va a apoyar en referencias históricas: no se analiza el sentido de la historia pero sí aparece como fuente de argumentación el concepto de historia. De ser un campo exclusivo del mundo erudito la historia pasa a convertirse en argumento de cualquier discusión, encontrándose en periódicos liberales como El Tribuno del Pueblo Español citas literales del código jurídico de las Partidas (siglo XIII); ${ }^{78}$ en el periódico liberal moderado El Universal, en la parte dedicada a explicar el significado de cada artículo de la Constitución de Cádiz, son frecuentes las referencias históricas y el fundamentar la explicación en su comprobación histórica:79 o en el periódico liberal (afrancesado) El Censor donde una parte de los artículos son estudios de historia contemporánea comparada entre España, Francia o Inglaterra, ${ }^{80}$ un tipo de estudios que propone el periódico denominar "estudio filosófico de la historia de la edad presente".81

No hay tema de debate que no se acompañe de un repaso histórico a veces exhaustivo del mismo, con menciones explícitas a documentos concretos y con citas detalladas, frecuentemente del código jurídico de las Partidas. No hay discusión en que no se mencione a la historia o a los historiadores, como Mariana (siglos XVI- XVII), ${ }^{82}$ para apoyar o negar una cuestión: "la historia nos ha dejado pruebas sensibles de haber tenido casi siempre[...]":83 "Nuestra antigua historia de España también nos lo comprueba";84 "Consultemos la historia, y ella nos servirá de guía, y de los hechos que nos ha conservado, podremos venir en conocimiento de los derechos". ${ }^{85}$

Al tiempo que no pueden prescindir de la utilización de la historia, algunos políticos son conscientes del carácter relativo e interpretativo de la misma, pues una misma referencia histórica puede servir para defender posiciones contrapuestas: "¿De qué servirá buscar hechos en la historia? Con hechos se puede justificar todo en el mundo, pues por desgracia la historia ofrece ejemplares aun para justificar las iniquidades de Bonaparte [...]." ${ }^{86}$ Es una toma de conciencia de que el pasado está sujeto a múltiples interpretaciones según los deseos de presente y de futuro.

El presente empieza a cobrar una omnipresencia en los escritos y en el pensamiento de los intelectuales de inicios del siglo XIX. Uno de los elementos que según François Hartog caracteriza a la modernidad fue la importancia que adquirió la memoria histórica. ${ }^{87}$ Pero este "memory boom" puede conducir a un "collapse of the future" por la insistencia constante de que el pasado esté presente y forme parte de nuestra experiencia coti- 
TORPEY, John. Making Whole What Has Been Smashed. On Reparations Politics. Cambridge/MA: Harvard University Press, 2006. p.19.

89

NORA, Pierre (dir.). Les Lieux de Mémoire. París: Gallimard, 1997. v.1-3.

90

Este tema ha sido particularmente estudiado por GARCIA TROBAT, Pilar. Constitución de 1812 y educación política. Madrid: Congreso de los Diputados, 2010, donde refleja cómo la lucha política se traslada o se plasma en la defensa a favor o en contra de las lápidas conmemorativas. 91

PALAREA BLANES, Juan. En: Diario de Sesiones de las Cortes Generales y Extraordinarias, 10/9/1820. Op. Cit., n.68, p.921.

92

Este Proyecto ha sido estudiado en detalle en GONZÁLEZ MANSO, Ana Isabel. El pensamiento político medieval como referente ideológico en la definición del Estado liberal español, 1814-1845. En: ROCHE ARNAS, Pedro (Coord.). El pensamiento político en la Edad Media. Madrid: Fundación Ramón Areces, 2010. p.463-473.

93

Politica. El Eco de Padilla, Madrid, 2/8/1821, n.2, p.10.

94

Esta cuestión se la plantea PALONEN, Kari. Contingencia, teoría política e historia conceptual. En: FERNÁNDEZ SEBASTIÁN, Javier; CAPELLÁN DE MIGUEL, Gonzalo (eds.). Conceptos políticos, tiempo e historia. Santander: Ed. Univ. Cantabria. p.351-376.

95

THIERRY, Augustin. Lettres sur I'Histoire de France, pour servir d'introduction à l'étude de cette histoire [1820]. París: Furne et Ce editeurs, 1856.

96

GUIZOT, François. Cours d'Histoire moderne [1828]. Bruselas: Société belge de librairie, Hauman et compagnie, edición de 1839. diana. ${ }^{88}$ A pesar de ello, en estos momentos apreciamos una interrelación bidireccional pasado-presente pero a su vez una proyección hacia el futuro a través de los deseos de construcción de una nueva sociedad por parte de sus protagonistas.

Durante el Trienio Liberal (1820-1823), y debido a la politización del concepto de historia, a éste se le va a añadir el significado de "memoria histórica", 89 con lo que supuso de memoria del grupo dominante. Esa memoria se demuestra en particular a través de la construcción de monumentos públicos en honor de los héroes de la patria o de lápidas conmemorativas:90 así tenemos la propuesta de un diputado liberal, Palarea, de que "para perpetuar la memoria del grandioso acontecimiento de que un ejército permanente se haya alzado para dar libertad a la Nación, acontecimiento único en la historia, debemos elevar un monumento que conserve aquel recuerdo." 91

Más significativo de la importancia que la función ideológica de la historia se plasme en la calle y llegue a la mayoría de los ciudadanos, es el Proyecto de Decreto presentado en las Cortes en junio de 1821 (y aprobado el 19 de marzo de 1822) para honrar la memoria de Juan de Padilla, Juan Bravo, Francisco Maldonado (guerra de las Comunidades, 1520-1523), y de Juan de Lanuza, Diego de Heredia y Juan de Luna (defensores de las libertades de Aragón, 1591).92 Héroes del pasado que serán identificados con los héroes del presente: así en el periódico liberal El Eco de Padilla se presentará a Riego (militar que consiguió con su pronunciamiento el 1 de enero de 1820 restablecer la Constitución de 1812) como el continuador de Padilla y de los comuneros: "pereció la libertad en los campos de Villalar" y no se recuperó hasta que Riego "tremoló en las Cabezas los pendones de la patria en 1 de enero de 1820".93

\section{IV. ¿Futuro dirigido o futuro contingente? ${ }^{94}$}

Como hemos ido viendo en los apartados anteriores, con la historia de la civilización se introdujo la búsqueda de unas leyes generales que debían de regir a la humanidad. Podemos considerar que Augustin Thierry ${ }^{95}$ estuvo más cerca al tipo de planteamientos históricos realizados por los liberales gaditanos y del Trienio, mientras que François Guizot ${ }^{96}$ claramente influyó en la concepción histórica de los liberales españoles de la década de los treinta y cuarenta. Para este autor, "je suis convaincu qu'il y a en effet une destinée générale de l'humanité" cuya historia en realidad englobaría el resto de las historias. Junto con los hechos sociales habría otros individuales más en relación con el alma humana que con la vida pública: serían los hechos relacionados con las creencias religiosas, las ideas filosóficas, las ciencias, las letras y las artes. Aunque estos pueden aparecer como factores de mejora individual, también habrían contribuido a la civilización de los pueblos. Este planteamiento permitía a los intelectuales españoles vincular sus creencias religiosas con una nueva manera de pensar la historia, al tiempo que les permitía desprenderse de los principios abstractos en los que habian sustentado sus concepciones anteriores. Pero creaba dudas existenciales tal y como lo manifestará claramente Jaime Balmes al interpretar el interés desbordado por la historia, que este autor observa desde la década de los treinta, por las profundas revoluciones que habian llevado a cuestionarse y buscar un sentido a la humanidad y a la sociedad. "¿Quién soy? ¿De dónde salí? ¿Cuál es mi destino?" se preguntan los seres humanos ante una situación de indiferentismo, de desarrollo de los intereses mate- 
97

BALMES, Jaime. El Protestantismo comparado con el Catolicismo en sus relaciones con la civilización europea. Tomo I. Manila: Imprenta de Sánchez, 1844. p.94.

98

Idem. Consideraciones políticas sobre la situación de España. En:____ (aut). Política y Constitución. Madrid: Centro de Estudios Constitucionales, 1988. p.64. (El destacado del texto es del original)

99

LAFUENTE Y ZAMALLOA, Modesto. Discurso Preliminar. Tomo I. En: (aut.). Historia General..., Op. Cit., p.3.

100

Ibidem, p.4.

101

DONOSO CORTÉS, Juan. Filosofía de la historia. Juan Bautista Vico. Tomo I. En:___ (aut.). Obras Completas. Madrid: Biblioteca de Autores Cristianos, 1946. p.542.

\section{2}

Idem. Consideraciones sobre la diplomacia. Tomo I. En:__ (aut.). Obras Completas. Op. Cit., p.102.

103

DONOSO CORTÉS, Juan. Bosquejos históricos. Tomo II. En: Obras Completas. Op. Cit., p.114.

104

Ibidem, p.113. riales, de progreso de las ciencias naturales y exactas y de protagonismo de los debates políticos. Balmes podía llegar a aceptar que un individuo fuese irreligioso pero "la familia y la sociedad no lo serán jamás. Sin una base donde pueda encontrar su asiento el edificio social, sin una idea grande, matriz, de donde nazcan las ideas de razón, virtud, justicia, obligación, derecho; ideas todas tan necesarias a la existencia y conservación de la sociedad [...], la sociedad desaparecería." ${ }^{.97}$

Si en los primeros decenios del siglo XIX progreso se vinculó con regeneración moral, a partir de la década de 1830 algunos autores como Balmes aprecian su vinculación con perfeccionamiento humano: "Progresar es marchar hacia delante, y si esto se ha de aplicar a la sociedad en sentido razonable, solo puede significar marchar hacia la perfección. Cuando la sociedad se perfecciona, progresa; cuando pierde su perfección, retrograda: para saber si hay progreso o no, toda la cuestión está en si hay nueva perfección o no."98 Pero para éste y otros intelectuales, la perfección solo se podría alcanzar a través de la religión. Esta misma asociación de progreso con perfeccionamiento humano la encontramos en Modesto Lafuente. Para este autor la Providencia pasa a ser un elemento integrante del concepto de progreso dado que el orden providencial conduce a la humanidad hacia el fin al que ha sido destinada, "la progresiva tendencia de la humanidad hacia su perfeccionamiento".99 En el perfeccionamiento de la humanidad el presente es producto del pasado y a su vez genera el futuro: "Cada individuo, cada familia, cada pueblo, cada nación, cada sociedad ha recibido su especial misión, como cada edad, cada siglo, cada generación tiene su índole, su carácter, su fisonomía, todo en relación a la vida universal de la humanidad." ${ }^{100}$

Por su parte, Juan Donoso Cortés, principal representante de una visión filosófica de la historia a partir de 1830, introdujo la noción de "la identidad moral de los hombres" en la que se funda la del género humano que da sentido a la unidad de la historia. ${ }^{101}$ Para Donoso solo hubo identidad moral al aparecer el cristianismo en las sociedades modernas: "Nacidos todos los pueblos de un origen común, habiendo visto pasar los mismos acontecimientos y habiendo estado sujetos a las mismas vicisitudes, todos obedecían a los mismos principios y marchaban bajo el imperio de unas mismas ideas; las transacciones entre ellos eran posibles, porque no habiendo incompatibilidad entre sus principios, podian adoptar una base reconocida por todos y ajustar después sus diferencias." $102 Y$ esas semejanzas vienen del hecho de que obedecen a unas leyes eternas y providenciales que hay que conocer pues son las que siguen las sociedades humanas en su evolución: sería el destino común de la humanidad de Guizot al que Donoso incorpora el elemento religioso. Por ello para Donoso "la Historia, considerada en general, es la narración de los acontecimientos que manifiestan los designios de Dios sobre la Humanidad y su realización en el tiempo, ya por medio de su intervención directa y milagrosa, ya por medio de la libertad del hombre." ${ }^{103}$ La historia sería la biografía del género humano y desde un punto de vista católico no habría más que una causa general de todos los sucesos humanos, "y esa es la Providencia divina" que actúa de manera natural o sobrenatural provocando "los acontecimientos directa, inmediata y milagrosamente". 104

Estos planteamientos darán pie a que la Providencia, menos protagonista, pero no olvidada, durante los primeros decenios del siglo XIX, vuelva a entrar en juego con fuerza. Pero nos podemos plantear a qué nivel actuaría esa Providencia: ¿Dios escribiría la obra, le daría sentido a la vida 
105

DE ZARAGOZA, José. Op. Cit., p.4.

106

LAFUENTE Y ZAMALLOA, Modesto. Prólogo. Op. Cit., p.IV.

107

MENÉNDEZ Y PELAYO, Marcelino. Discurso preliminar..., Op. Cit., p.68.

Recebido para publicação em 03 de novembro de 2014

Aprovado em 15 de dezembro de 2014 y a la historia o la finalidad de la historia sería buscar la mano de Dios en los principios eternos que caracterizarian a la humanidad? Esta segunda interpretación implica en nuestra opinión, un grado inferior de meta o plan divino y permitiría un mayor grado de libertad humana. La podemos ver reflejada en los escritos de José de Zaragoza. Para este académico el principal objetivo de la historia, su utilidad real, era mostrar que "hay principios eternos en el hombre, lo propio que en la naturaleza inanima$d a, y$ que estos principios se encuentran en todos los tiempos bajo formas diversas, pero idénticas siempre en el fondo, y ello es también que en buscar estos principios eternos se encierra el deber del historiador, y que en su comprensión está toda la utilidad de las investigaciones y estudio de lo pasado." ${ }^{105}$ Esta interpretación consiente un protagonismo del ser humano y así pues dar un sentido a la historia más moderno, menos dependiente en exclusividad de la divinidad.

De todas formas en la mayoría de los casos se trata de una toma de conciencia de la inestabilidad que produjo la aceleración de los tiempos y de la necesidad de encontrar elementos de seguridad: "Nunca más que en tales ocasiones necesita el pensamiento público meditar sobre la marcha constante de la humanidad para no desesperar por los males que experimenta, descubriendo en la ley providencial e infalible que rige sus destinos, los secretos y los consuelos de menos azaroso porvenir." ${ }^{106}$ Y por lo general esa seguridad vendrá de la mano del concepto moral, entendido éste en un sentido muy amplio y pudiendo englobar elementos religiosos.

El volver a recurrir a la Providencia tendrá a su vez consecuencias políticas, de tal manera que encontraremos todo un arco de posturas que irán desde la defensa por parte de algunos intelectuales de la supeditación de lo político a lo religioso (en la línea defendida por Joseph de Maistre y Louis de Bonald para los cuales la voluntad de Dios supondría la constante explicación de los acontecimientos humanos), a posturas que abogarán por dar un mayor protagonismo al ser humano y a la política sobre la religión. Posturas totalmente laicas o agnósticas serán todavía muy poco frecuentes en el periodo estudiado.

De lo que no nos cabe duda es que estas posturas condicionarán la manera de escribir la historia a partir de ese momento: la explicación racional del sentido de la historia se entremezclará con una interpretación católica de la misma a dosis variables según la sensibilidad del intelectual considerado. A modo de colofón recogemos la siguiente afirmación de Menéndez Pelayo en 1877 que expresa perfectamente esa simbiosis: "Gracias a Dios, no soy fatalista, ni he llegado ni llegaré nunca a dudar de la libertad humana, ni creo, como los hegelianos, en la identidad de las proposiciones contrarias, verdaderas las dos como manifestaciones de la idea o evoluciones diversas de lo Absoluto, ni juzgo la historia como simple materia observable y experimentable al modo de los positivistas. Católico soy, y, como católico, afirmo la providencia, la revelación, el libre albedrío, la ley moral, bases de toda historia. Y ¿para cuándo guardas la imparcialidad?, se me dirá. ¿No es ésa la primera cualidad del narrador, según rezan todos los tratados de conscribenda historia desde Luciano acá? La respuesta es fácil: mi historia será parcial en los principios; imparcial, esto es, veracísima, en cuanto a los hechos". 107 